\title{
Effect of Hydroalcholic Extract of Curcuma longa on Adriamycin-Induced Renal Damage in Rats
}

\author{
Mohebbati R. ${ }^{1}$ MSc, Abbasnezhad A.A. ${ }^{2}$ PhD, Khajavi Rad A.* MD, MPH, \\ Haghshenas M. ${ }^{1}$ MSc, Khazdeir M.R. ${ }^{1}$ MSc
}

\begin{abstract}
*Physiology Department, Medicine Faculty, Mashhad University of Medical Sciences, Mashhad, Iran 1Physiology Department, Medicine Faculty, Mashhad University of Medical Sciences, Mashhad, Iran 2Basic Sciences Department, Medicine Faculty, Gonabad University of Medical Sciences, Gonabad, Iran
\end{abstract}

\begin{abstract}
Aims: Adriamycin is one of the anti-cancer medications. Nevertheless, the medication causes renal damage. Curcuma longa has anti-inflammatory and anti-oxidant effects. The aim of this study was to determine the effects of hydroalcoholic extract of Curcuma longa on renal damage due to Adriamycin in the rat.

Materials \& Methods: In the experimental study, 32 male Wistar rats were studied. Via simple random method, the rats were divided into four groups including control, Adriamycin ( $5 \mathrm{mg} / \mathrm{Kg}$ ), Curcuma longa extract $(1000 \mathrm{mg} / \mathrm{Kg}$ ), and Curcuma longa extract with Adriamycin groups. The groups underwent 5week treatment. 24-hour urine samples were collected at days $0,6,10,14,21$, 28 , and 35 , to measure glomerular filtration rate. The left kidney of the animal was used to determine the renal damage percentage. Data was analyzed by SPSS 16 software using one-way ANOVA, Tukey's post-hoc, and paired T tests.

Findings: Mean of glomerular filtration rate in Adriamycin group significantly decreased at days 21 and 35 compared to days 0 and 6 . In addition, it significantly increased in Curcuma longa extract group at days $10,14,21$, and $28(\mathrm{p}<0.05)$. The renal damage percentage significantly increased in Adriamycin $(\mathrm{p}<0.001)$ and Curcuma longa extract with Adriamycin $(\mathrm{p}<0.01)$ groups than control group. In addition, it significantly decreased in Curcuma longa extract group, as well as Curcuma longa extract with Adriamycin group, compared to Adriamycin group ( $\mathrm{p}<0.001)$.

Conclusion: Hydroalcoholic extract of Curcuma longa reduces the renal damage percentage caused by Adriamycin in the rat, while improves glomerular filtration rate.
\end{abstract}

\section{Keywords}

Curcuma longa [https://www.ncbi.nlm.nih.gov/mesh/68030024];

Renal Failures [https://www.ncbi.nlm.nih.gov/mesh/68051437];

Glomerular Filtration Rate [https://www.ncbi.nlm.nih.gov/mesh/68005919];

Adriamycin [https://www.ncbi.nlm.nih.gov/mesh/68004317]

\footnotetext{
*Corresponding Author

Tel: +98 (51) 38828565

Fax: +98 (51) 38828564

Address: Department of Physiology, School of Medicine, Azadi Square, Mashhad, Iran. Postal Code: 917794-8564

khajavirada@mums.ac.ir

Received: January 12, $2015 \quad$ Accepted: May 11, 2016 ePublished: October 1, 2016
} 
مقدمه

نفروياتى عبارت است از كاهش نسبى عملكرد كليه كه با سندروم

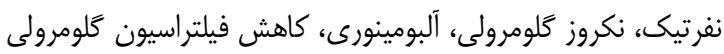

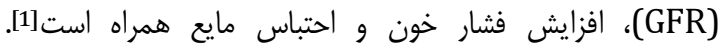
نفروياتى توسط آسيب يودوسيتها بلددنبال نكروز كلومرولى، التهاب

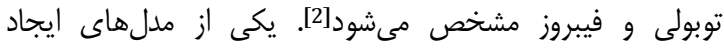

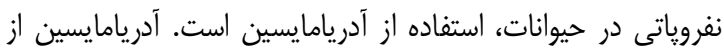

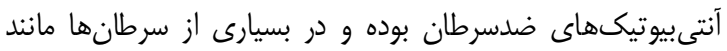

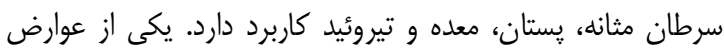

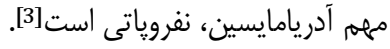

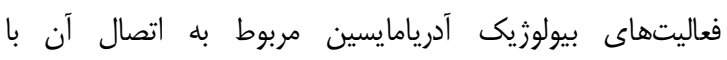
دىاكسىريبونو كلئيكاسيد (DNA) در بين جفتبازهاى مجاور در ساختمان مارييج مضاعف است. اين خصوصيت سبب مهار آنزيههاى درگير در فرآيندهاى رونويسى و همانندسازى DNA

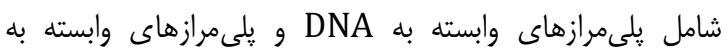

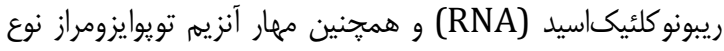
r مىشود و راديكالهاى آزاد توليد مى كند، زنجيره قطعهقطعه كرده و نيز سبب ازهم گسيختخى ساختمان غشا مىشود. آدريامايسين در سطح سلولى داراى اثر مهارى سريع و وابسته به

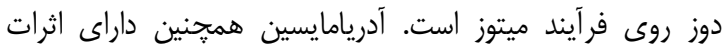
سركوبكنندگى سيستم ايمنى است و در واكنش اكسيداسيون - احيا نيز نقش دارد [4].

آدريامايسين سبب افزايش دفع N- N- استيل كلوخزآمين (NAG)، كليكوز آمينوگليكان (GAG) و فيبرونكتين از ادرار، كاهش سرعت

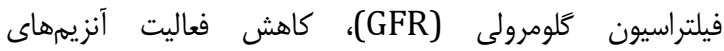
آنتىاكسيدان از قبيل كلوتاتيون و كلوتاتيونيراكسيداز، افزايش القاى

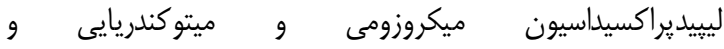

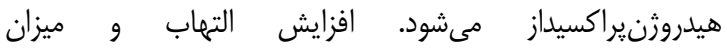

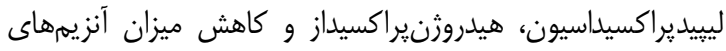

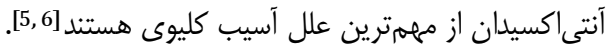

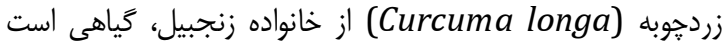
علفى و يايا به ارتفاع ه/1-1 متر و داراى ريزوم متورمى است كه از آن هندين ساقه هوايى خارج مىشود. قسمت مورد استفاده غذايى و

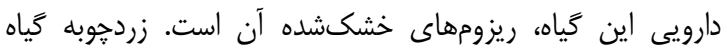

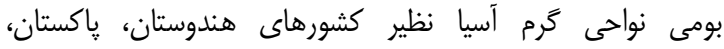

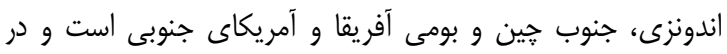

ايران رويش ندارد[7].

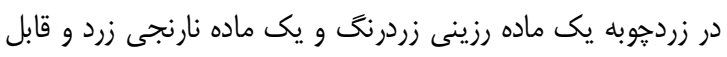

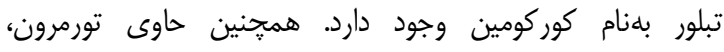
زينجى برون و نوعى الكل بلنام تورمرول است و8.

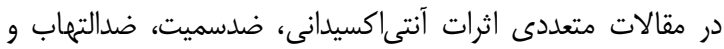

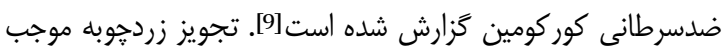

اثر عصاره آبى - الكلى زردجيوبه بران آنسيب كليوى ناشى از آدريامايسين در موشىهاى صحرايى

MSc رضا محبتى

كروه فيزيولوزى، دانشكده يزشكى، دانشكاه علوم يزشكى مشهلد، مشهر، ايران

عباسعلى عباسنزاد PhD

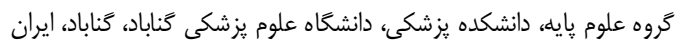

MD, MPH "بوالفضل خواجوىر اد

كروه فيزيولوزى، دانشكده يزشكى، دانشعاه علوم يزشكى مشهرد، مشهل، ايران ميلاد حقشناس MSc

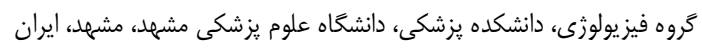
محمدر ضا خزدير MSc

كروه فيزيولوزى، دانشكده يزشكى، دانشخاه علوم يزشكى مشهد، مشهر، ايران

جكيده

اهداف: آدريامايسين از داروهاى مهم ضدسرطان است كه باعث آسيب

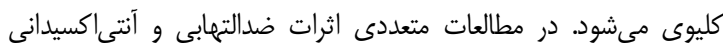

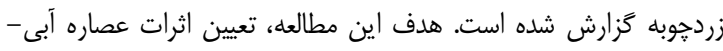

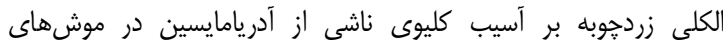
صحرايى بود.

مواد و روشها: در اين مطالعه تجربى، זس سر موش صحر ايیى نر نزاد

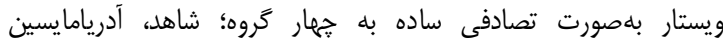

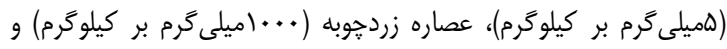

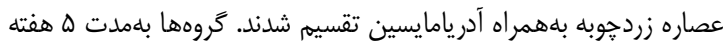

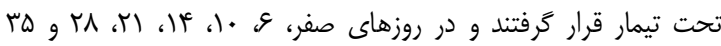

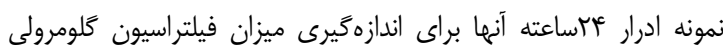
جمعآورى شد. براى تعيين درصد آسيب كليوى از كليه سمت جِ

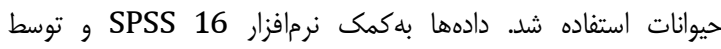

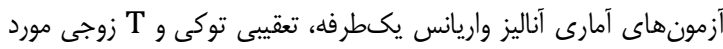
تجزيه و تحليل قرار گرفتند.

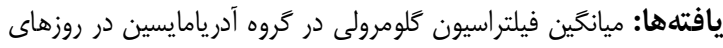

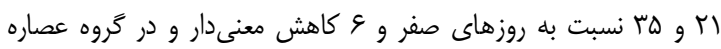

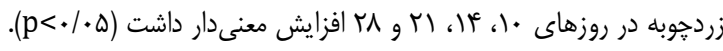

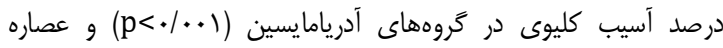

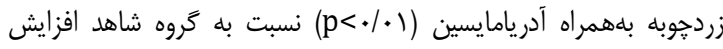

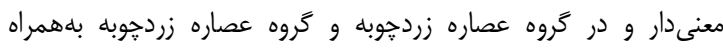

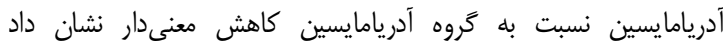
.$(\mathrm{p}<\cdot /+\cdot 1)$ نتيجه كَيرى: عصاره آبى - الكلى زردجوبه، درصد آسيب كليوى ناشى از آدريامايسين در موشهاى صحرايى را كاهش داده و سبب بهابي بهبود ميزان فيلتراسيون كلومرولى مى شودام. كليدوازهها: زرديوبه، آسيب كليوى، ميزان فيلتراسيون كلون ملومرولى، آدريامايسين

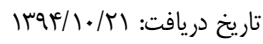

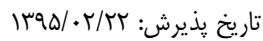

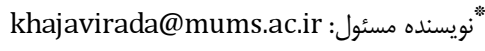




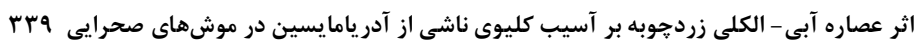

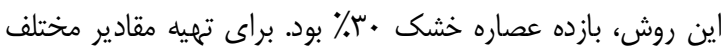

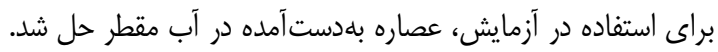

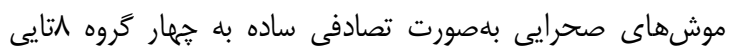

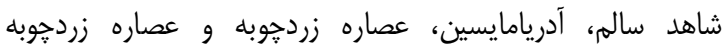

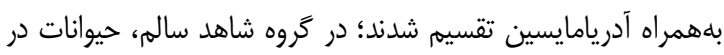

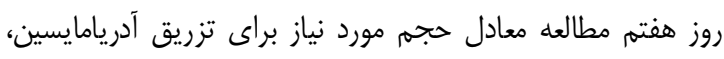

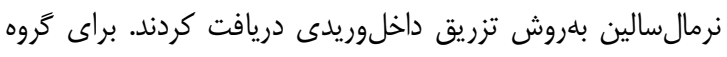

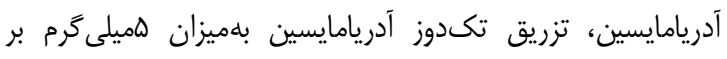

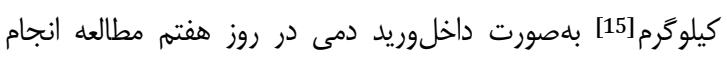

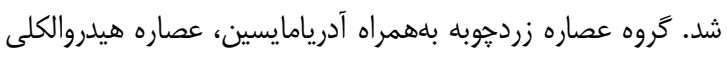

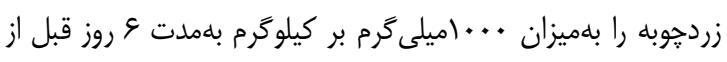

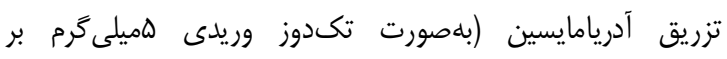
كيلوكرم) در روز هفتم و سيس بلهمدت

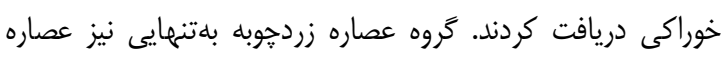

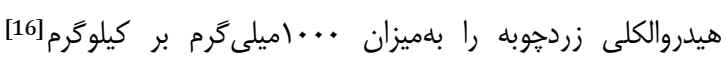
بدون تزريق آدريامايسين دريافت نمودند.

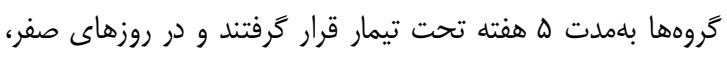

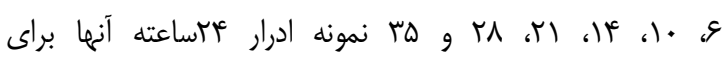

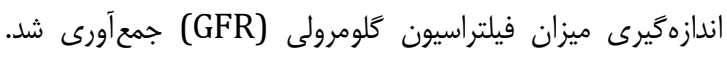

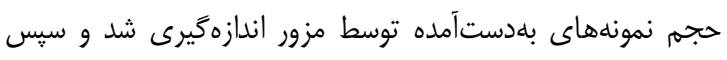

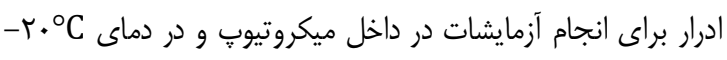

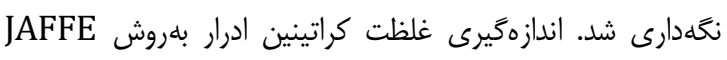
براساس دستور كيت مربوطه (يارسآزمون؛ ايران) و توسط دستخاه

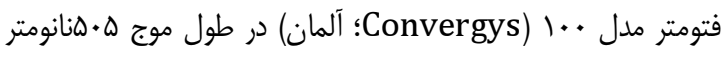

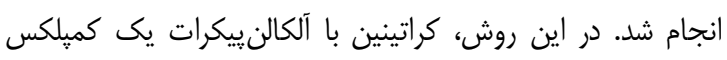
رنخى تشكيل مىدهد كه شدت رنغ ايجادشده متناسب با مقدار

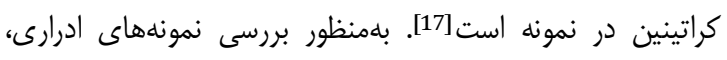

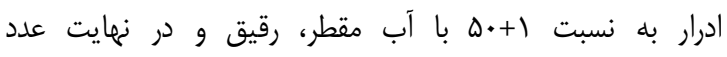
بلهدستآمده در اله ضرب شد. ميزان فيلتراسيون كلومرولى (كليرنس كراتينين بر حسب ميلىليتر در دقيقه) از طريق فرمول؛

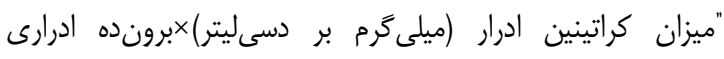

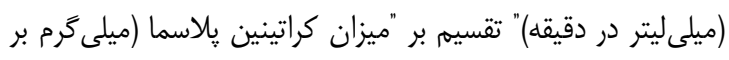
دسى ليتر)" محاسبه شد.

براى تعيين درصد آسيب كليوى، از كليه سمت خِّ حيو حيوانات

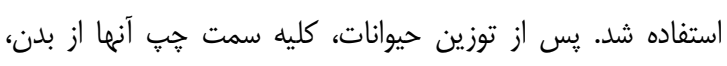
خارج و در يك برش طولى نصف شد. سيس دو نيمه با محلول

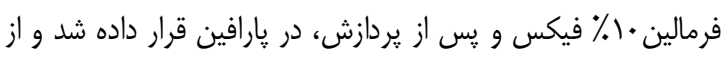

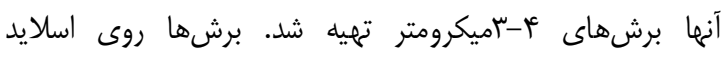

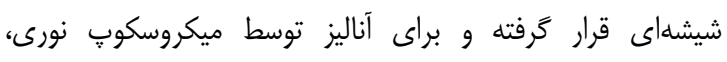

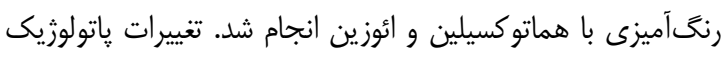

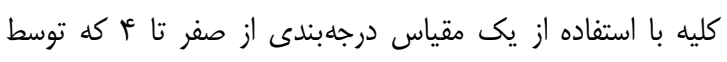
كورينَّ و همكاران [18] مطرح شده، به اين صورت ثبت شدئ صفر
كاهش ميزان كلسترول و ترى كليسريد خون و مهار اكسيداسيون LDL

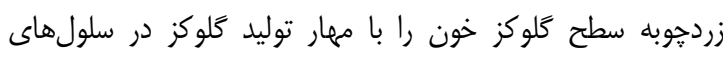

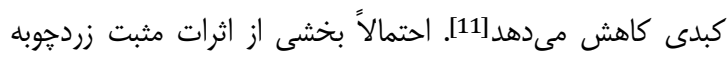

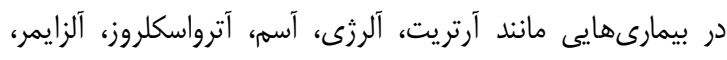

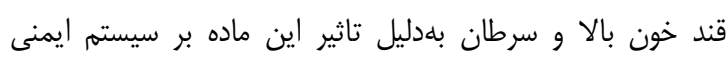

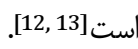

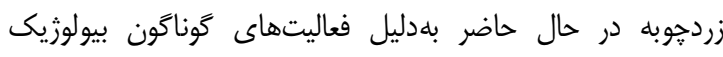

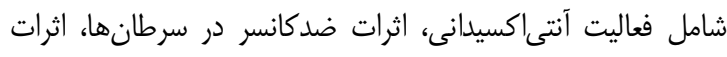

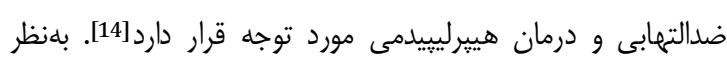

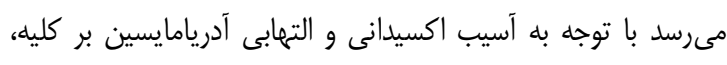

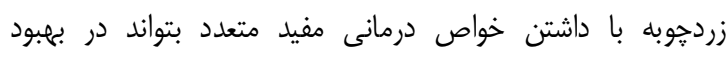

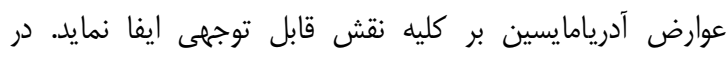

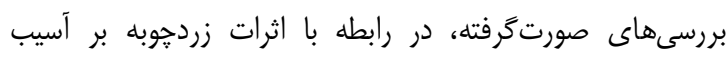

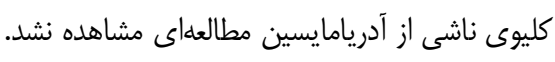

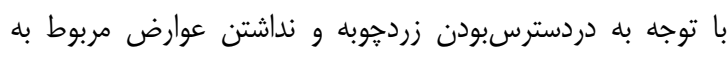

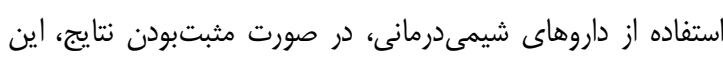

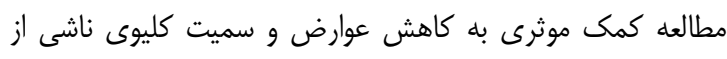

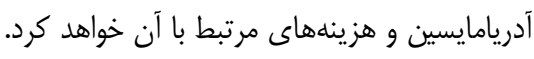

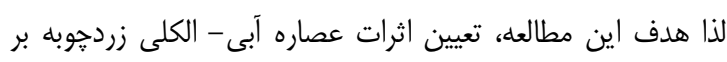
آسيب كليوى ناشى از آدريامايسين در موشهائ صحرائ بيى بود.

\section{مواد و روشها}

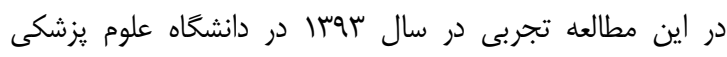

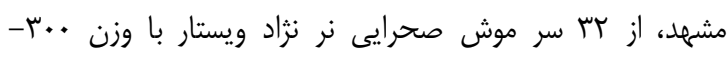

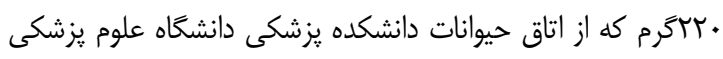

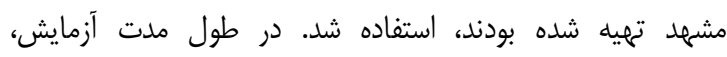

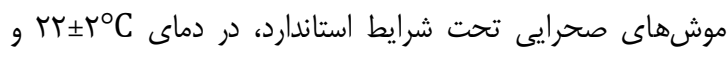

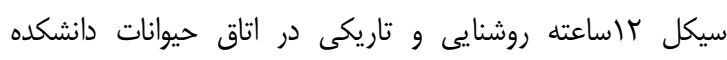

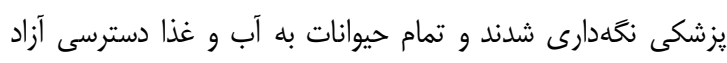

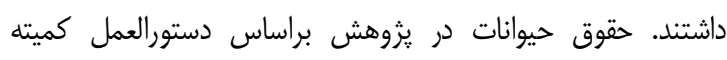

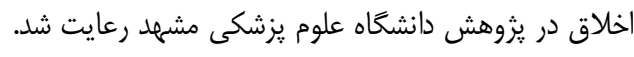

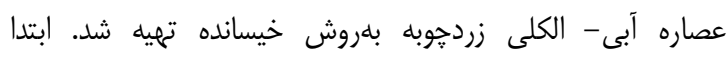

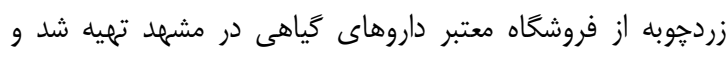

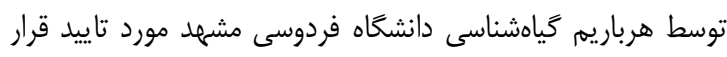

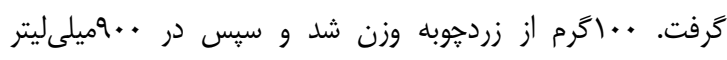

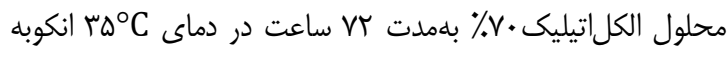

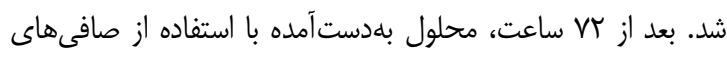

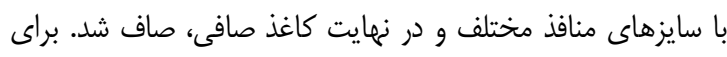

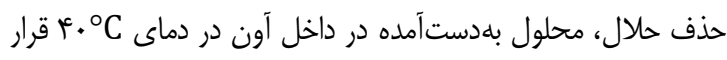

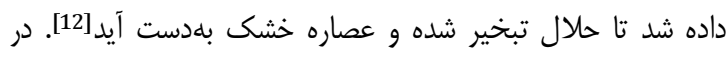


روزهاى صفر و 8 اختلاف معنىدارى نشان نداد. در گروه عصاره

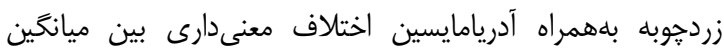
GFR

$$
\text { و و مشاهده نشد (جدول (). }
$$

\begin{tabular}{|c|c|c|c|}
\hline آدروه زرديوبه و & زروره عصاره & 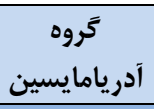 & تروه شاهد \\
\hline . $/ \mu q \pm \cdot / \cdot r$ & $\cdot / \mu_{ \pm} \cdot / \cdot 1$ & $. / 4 V \pm . / .9$ & 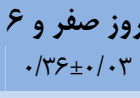 \\
\hline$. / 4 y_{ \pm} \cdot / \cdot 4$ & $\cdot / N_{ \pm} \pm \cdot / \cdot e^{* *}$ & $\cdot / \% \Delta \pm \cdot / \cdot \Delta$ & 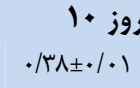 \\
\hline$\cdot / \mu \Lambda \pm \cdot / \cdot \varphi$ & $\cdot / K T \pm \cdot / \cdot 1^{*}$ & $\cdot / r Y \pm \cdot / \cdot \Delta$ & 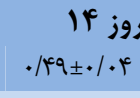 \\
\hline$\cdot / R \cdot \pm \cdot / \cdot r$ &.$/ \mu r_{ \pm \cdot \cdot / . r^{*}}$ & $\cdot / 19 \pm * / . r *$ & 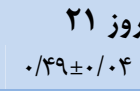 \\
\hline$\cdot / 4 \cdot \pm \cdot / \cdot r$ & $\cdot /\left.\right|^{\prime} \mid \pm \cdot / \cdot r^{*}$ & $\cdot / r_{ \pm \pm \cdot \cdot / \cdot \varphi}^{*}$ & נروز ג ג ג \\
\hline$\cdot / \% q_{ \pm} \cdot / \cdot \Delta$ & . & $\cdot / r_{ \pm} \cdot / \cdot r^{*}$ & 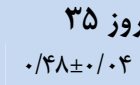 \\
\hline
\end{tabular}

تغييرات وزن در طول مطالعه در كروه دريافت كننده آدريامايسين و دروافي نيز در تروه دريافت كننده زرديوبه بهاهمراه آدرياه

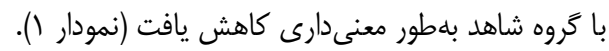

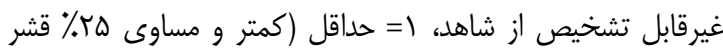

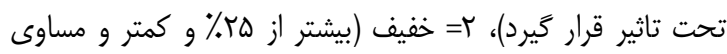

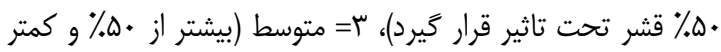

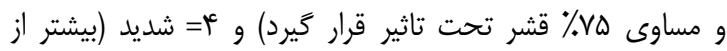

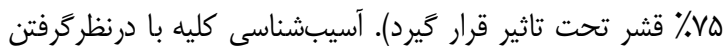

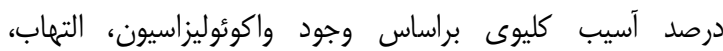

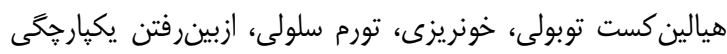

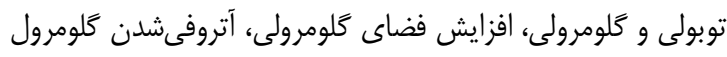

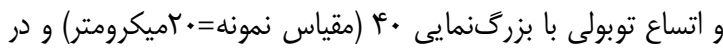

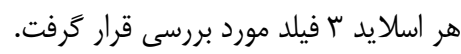

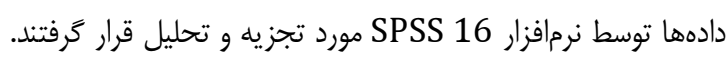

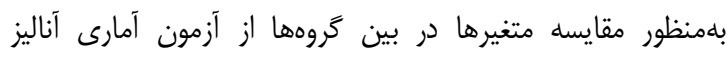

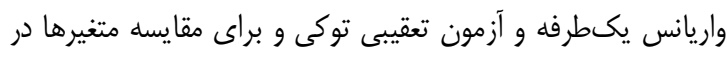

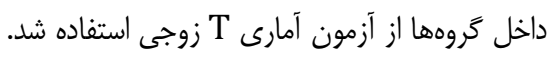

\section{يافتهها}

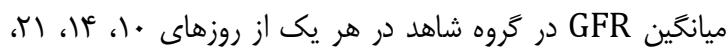

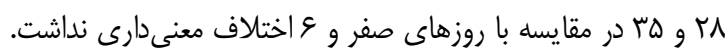

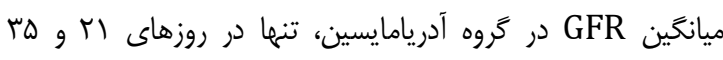

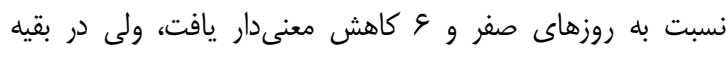

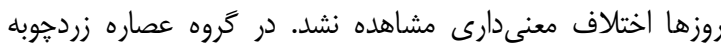

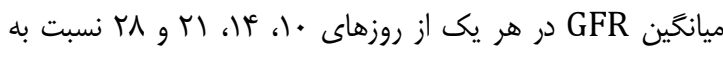

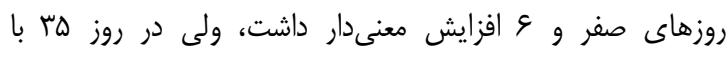

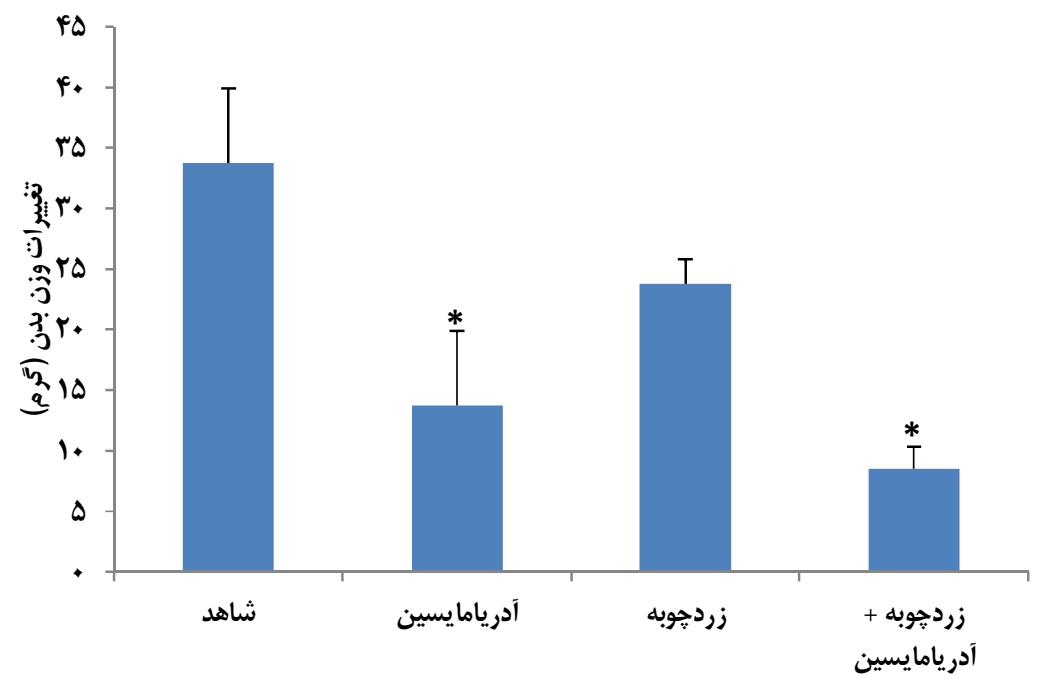

نمودار ( ) بررسى تغييرات وزن در مقايسه با كروه شاهد با استفاده از آزمون آناليز واريانس يكطرفه و آزمون تعقيبى توكى (*ه+/·p نسبت به گروه شاهد)

آسيب كليوى در گروه عصاره زردجوبه و گروه عصاره زردجوبه

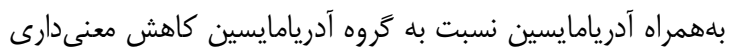

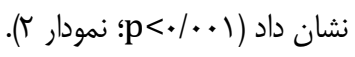

درصد آسيب كليوى در هر يك از گروههاى آدريامايسين

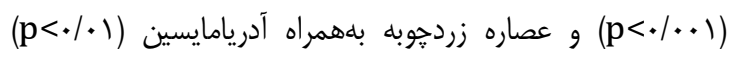

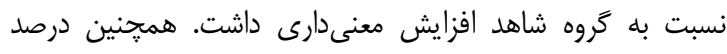

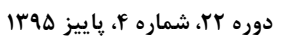
فصلنامه افق دانش به 


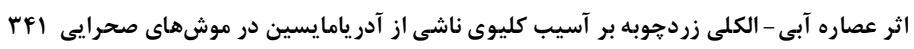

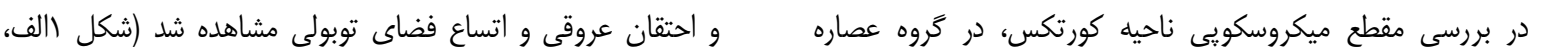

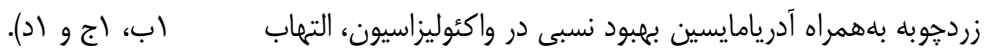

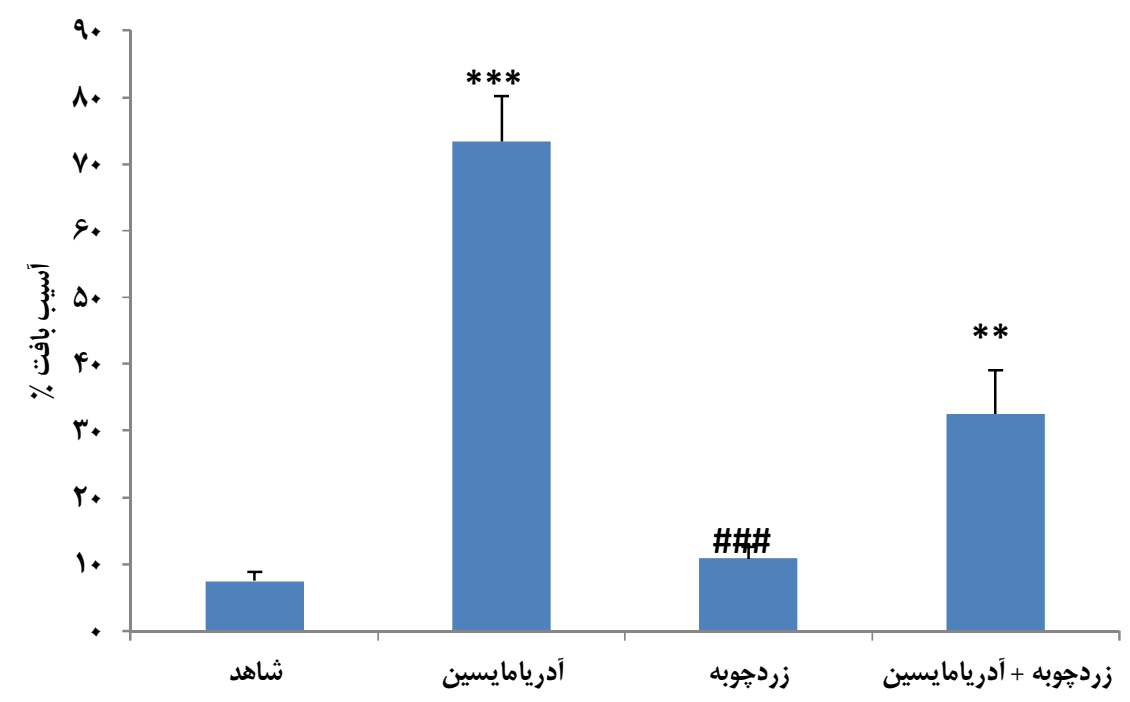

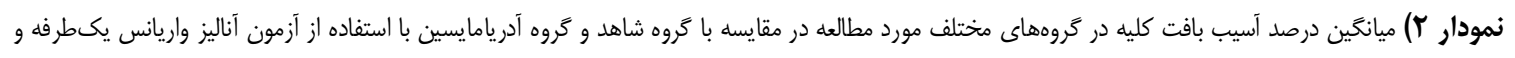

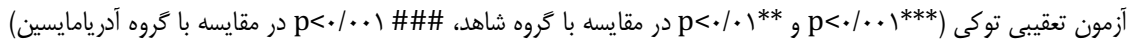
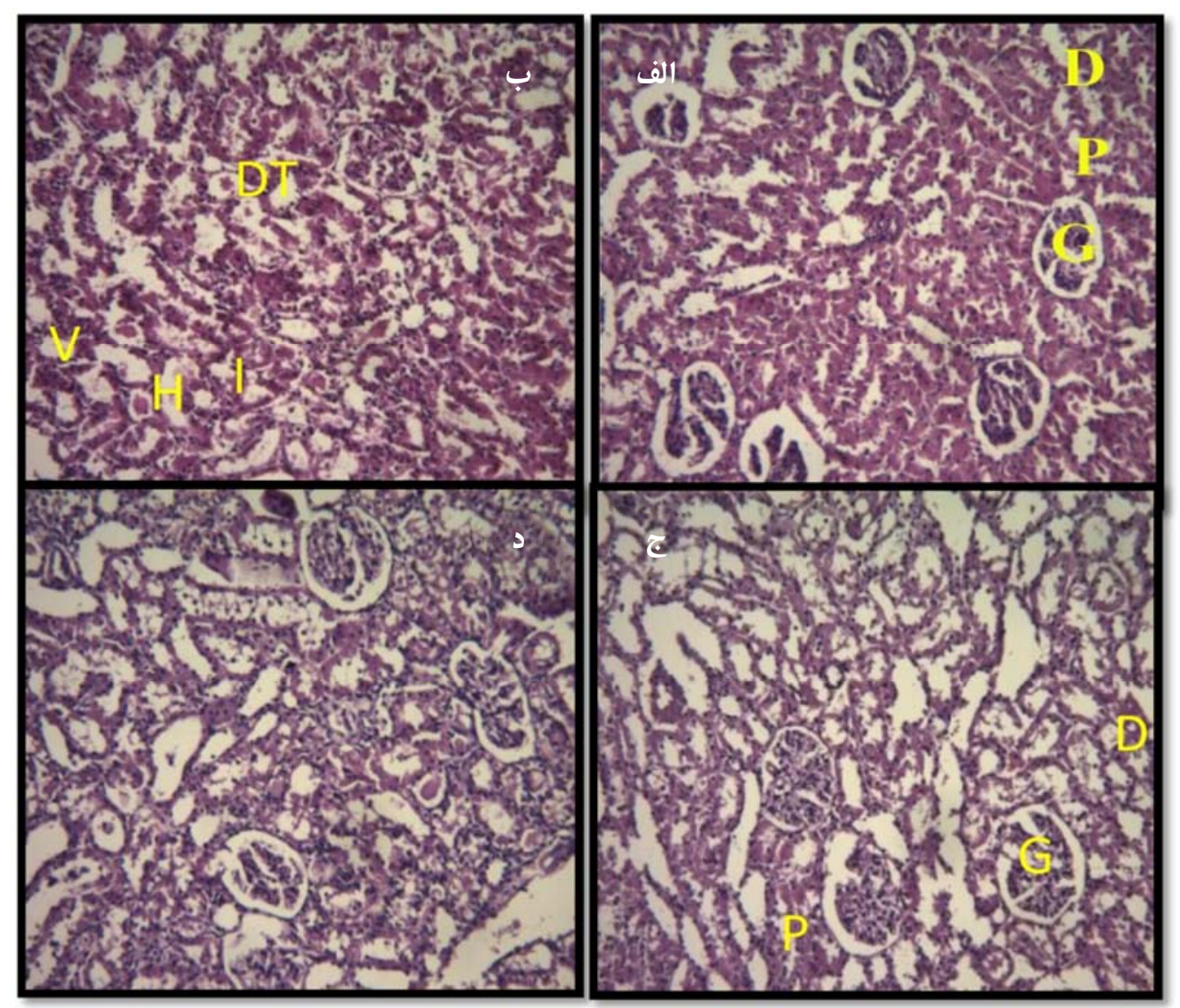

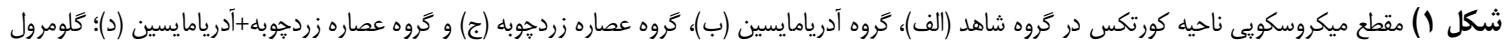

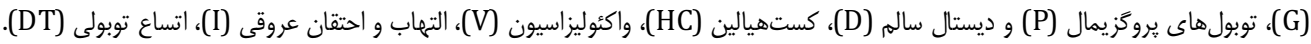


ميانكَين وزن حيوانات در پايان مطالعه در كروه دريافتكننده

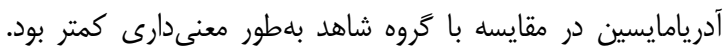

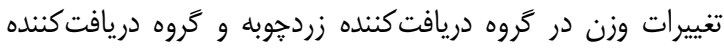

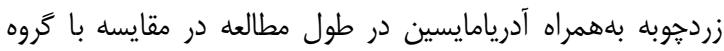
شاهد كمتر بود، ولى تفاوت معنى دارى نداشت.

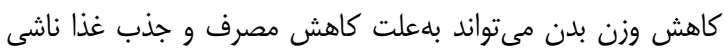

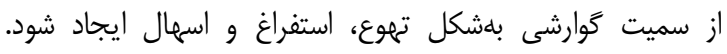

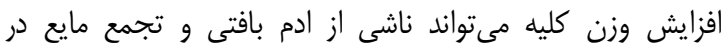

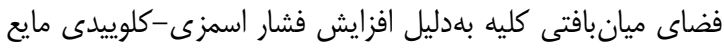

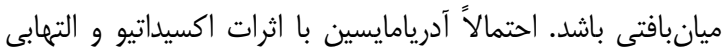

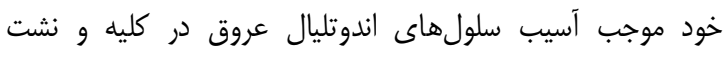

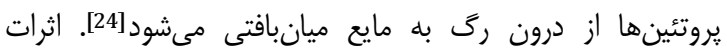

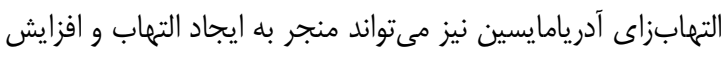

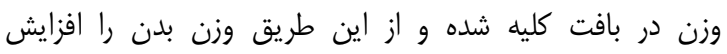

دهد[25].

كاهش وزن بدن در مدلهاى حيوانى تزريق آدريامايسين در

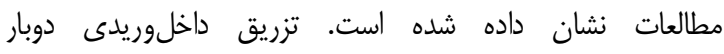

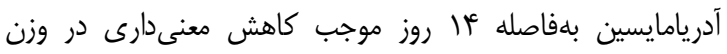

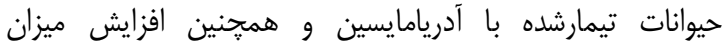

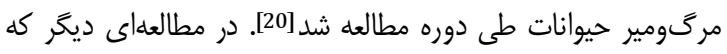

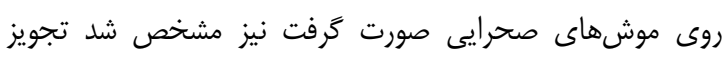

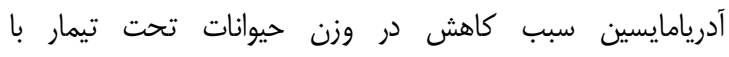
آدريامايسين مىشود[26].

نتايج اين بررسى نشان داد تجويز عصاره زرديوبه باعث بهيبود

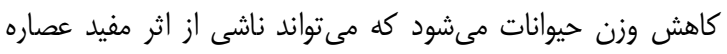

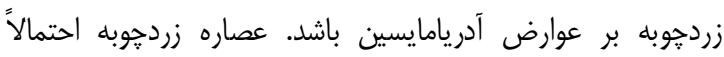

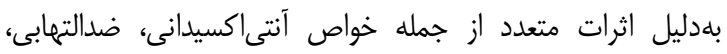

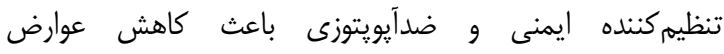

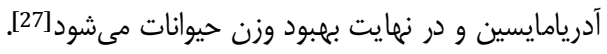

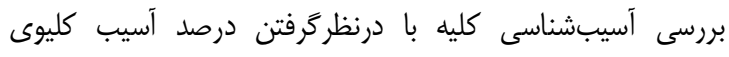

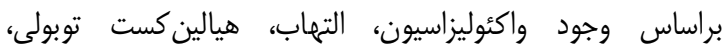

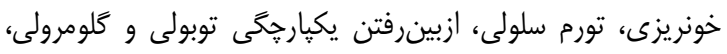

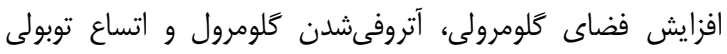

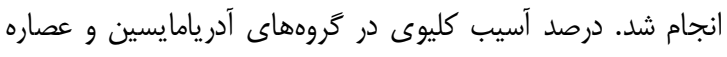

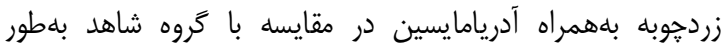

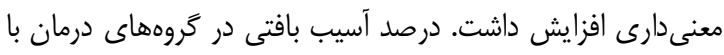

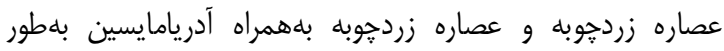

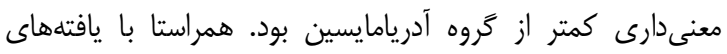

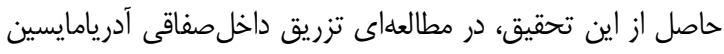

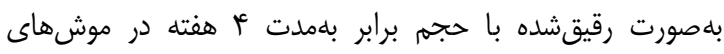

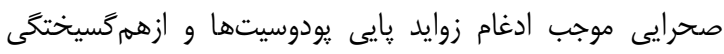

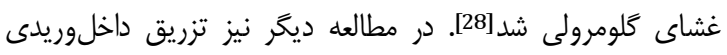

آدريامايسين با كاهش عملكرد كليه از طريق كاهش GFR،

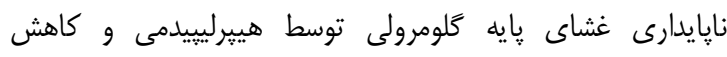

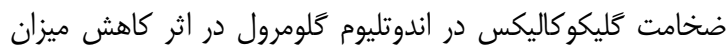

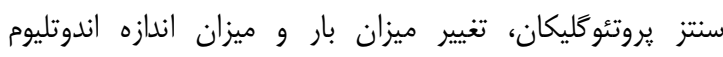

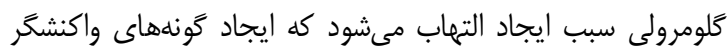

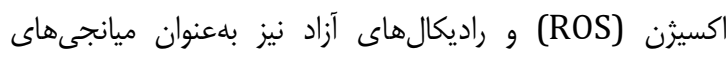

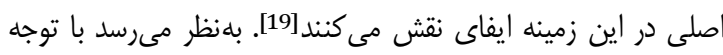

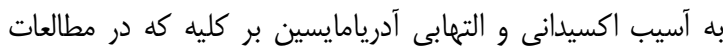

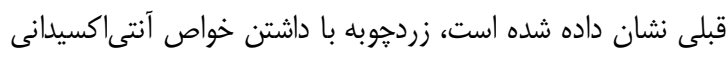

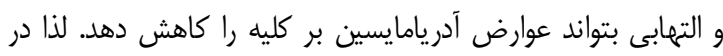

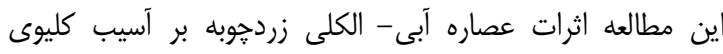

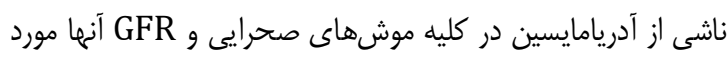

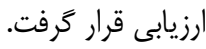

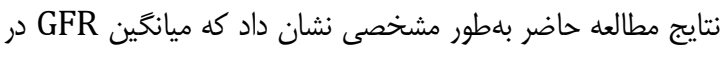

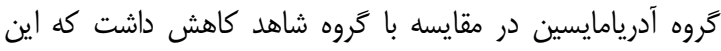

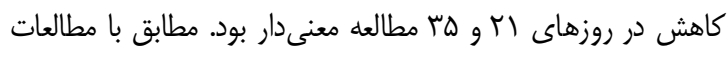

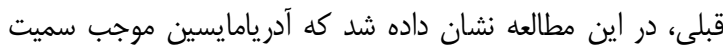

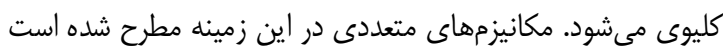

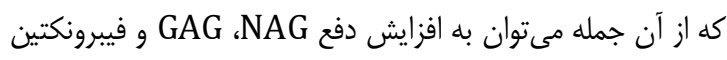

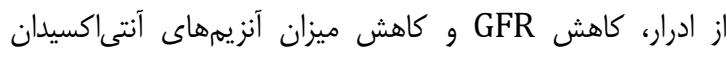

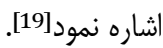

مطالعات انجامشده نشان مىدهد كه تزريق داخلوريدى دوبار

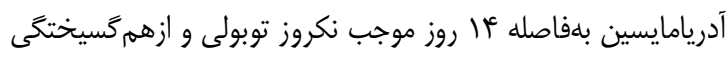

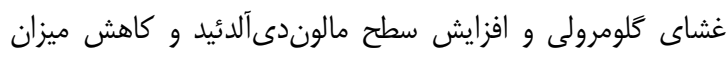

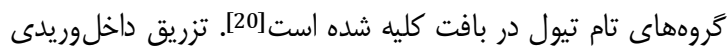

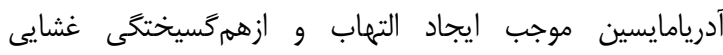

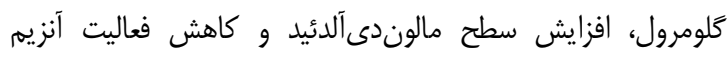

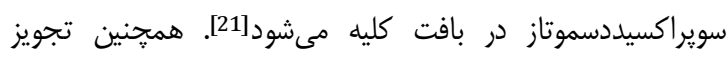

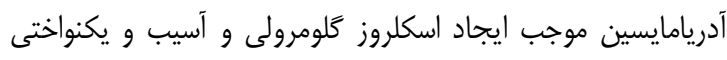

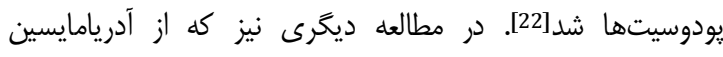

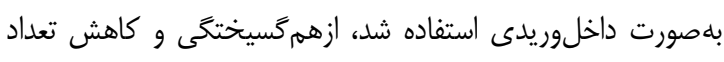

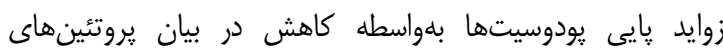
يودوسيتى نفرين و يدوسين ايجاد شد [23].

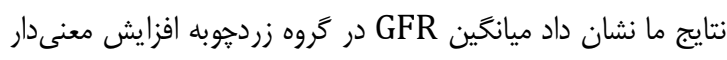

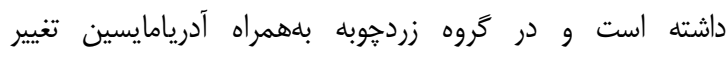

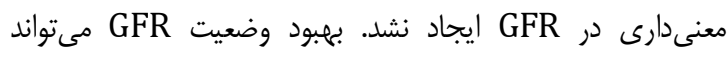

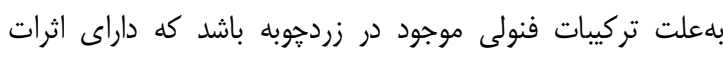

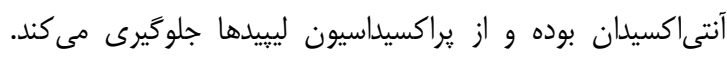

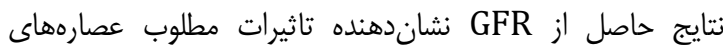

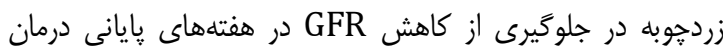
نسبت به روز شاهد در همان گروه است. 


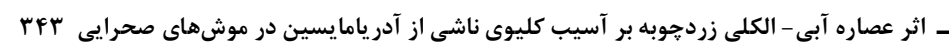

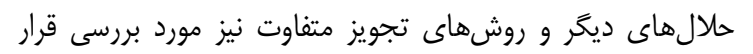

گيرد.

نتيجحه كيرى

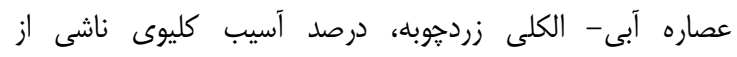

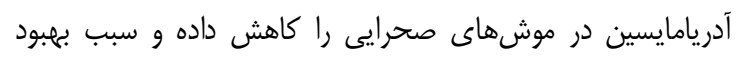

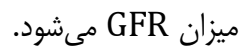

تشكر و قدردانى: نويسندكان بر خود لازم مىدانند كه از

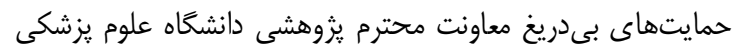
مشهد سياسخزارى نمايند.

تعارض منافع: هيج گونه تعارض منافع توسط نويسندًان بيان

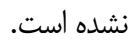

تاييديه اخلاقى: تاييديه اخلاقى اين يزوهش از كميته اخلاق يزشكى دانشخاه علوم يزشكى مشهر اخذ شده آيده است.

منابع مالى: اين مقاله حاصل يك طرح تحقيقاتى است و از

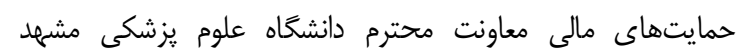

$$
\text { برخوردار بوده است. }
$$

\section{منابع}

1- Lee VW, Harris DC. Adriamycin nephropathy: A model of focal segmental glomerulosclerosis. Nephrol. 2011;16(1):30-8.

2- Balakumar P, Chakkarwar VA, Kumar V, Jain A, Reddy J, Singh M. Experimental models for nephropathy. J Ren Angiotensin Aldosterone Syst. 2008;9(4):189-95.

3- Mohebati R, Abbasnezhad AA, Khajavi Rad A, Mosavi $M$, Haghshenas M. The effects of hydroalcholic extract of Nigella sativa on doxorubicin-induced renal functional damage in rats. Horizon Medi Sci. 2015;21(4):1-10. [Persian]

4- Saito TE. Adriamycin: A review of its use, and guidelines for administration. Cancer Nurs. 1978;1(2):169-74.

5- Jeansson M, Björck K, Tenstad O, Haraldsson B. Adriamycin alters glomerular endothelium to induce proteinuria. J Am Soc Nephrol. 2009;20(1):114-22.

6- Venkatesan N, Punithavathi D, Arumugam V. Curcumin prevents adriamycin nephrotoxicity in rats. $\mathrm{Br}$ J Pharmacol. 2000;129(2):231-4.

7- Eigner D, Scholz D. Ferula asa-foetida and Curcuma longa in traditional medical treatment and diet in Nepal. J Ethnopharmacol. 1999;67(1):1-6.

8- Akram M, Shahab-Uddin AA, Usmanghani K, Hannan A, Mohiuddin E, Asif M. Curcuma longa and curcumin: A review article. Rom J Biol. 2010;55(2):65-70.

9- Huang MT, Wang ZY, Georgiadis CA, Laskin JD, Conney $\mathrm{AH}$. Inhibitory effects of curcumin on tumor initiation by benzo [a] pyrene and 7, 12-dimethylbenz [a] anthracene. Carcinog. 1992;13(11):2183-6.

10- Ramirez-Tortosa MC, Mesa MD, Aguilera MC, Quiles JL, Baro L, Ramirez-Tortosa CL, et al. Oral administration of a turmeric extract inhibits LDL oxidation and has
دوبار آدريامايسين بهفاصله أل روز موجب نكروز توبولى و و

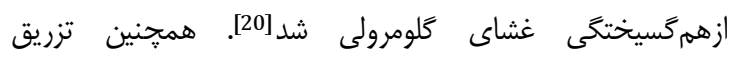

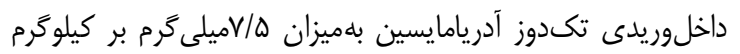
موجب ايجاد اتساع توبولى و هيالين كست شد [29]. نتايج مطالعه ديخرى نيز نشان داد تزريق داخلوريدى آدريامايسين بلهيزان

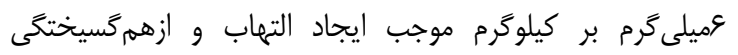

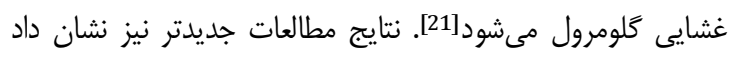

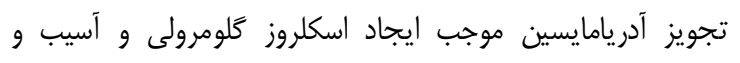

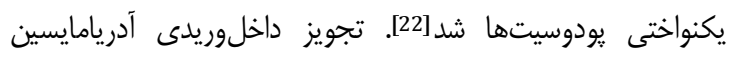

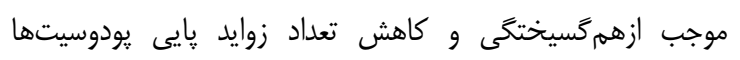
بلواسطه كاهش در بيان يروتئينهاى يودوسيتى نفرين و يودوسين

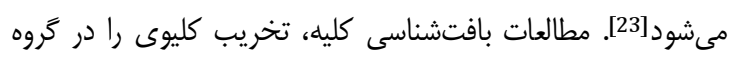

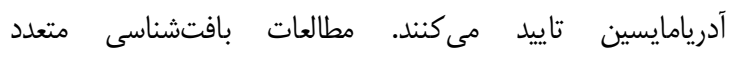

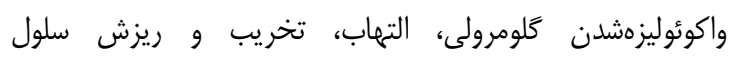

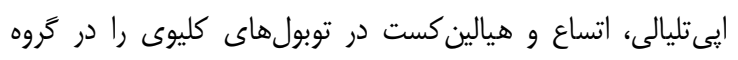
آدريامايسين نشان دادند[130,31] در مطالعات گَوناگون به خواص ضدالتهابى و آنتىاكسيدانى زردجهوبه اشاره شده است. بلنظر مىرسد كه اين اثرات مطلوب عصارههاى زردجوبه در افزايش فعاليت آنزيم سويراكسيددسموتاز و گروههاى

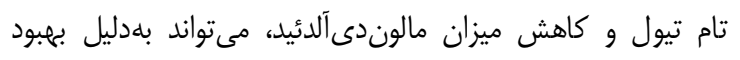
وضعيت آنتىاكسيدانى و كاهش تشكيل ڤيراكسيدهاى ليبيد ايجاد شود. احتمالاً اثر حفاظتى عصاره زردجوبه بلهعلت وجود كور كومين بردين موجود در زردجوبه و همجنين ساير فلاوونوئيدها و و تركيبات يلىفنولى موجود در آن است كه داراى خواص آنتىاكسيدانى قابل

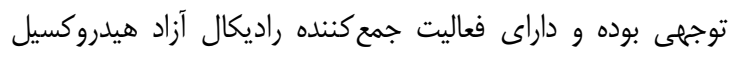

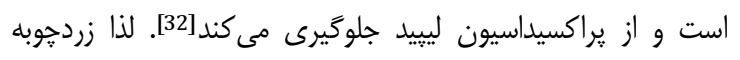
بلهعلت داشتن تركيبات يلىفنولى و خواص آنتىاكسيدانى ممكن است موجب بهبود تخريب بافتى در نفروياتى ناشى از سميت

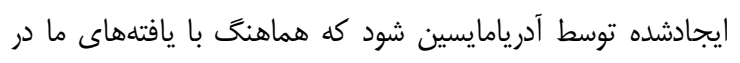
ثزوهش حاضر است. آسيب اكسيداتيو و اثرات التهابى نقش مهرونى در در نفروياتى ناشى از

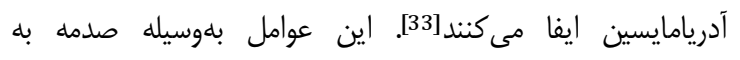
غشاهاى كلومرولى و از طريق صدمه به سلولهاى اندوتليال، سلولهاى يودوسيت و غيره باعث نفروياتى مىشوند. مطالعات

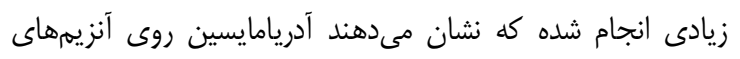

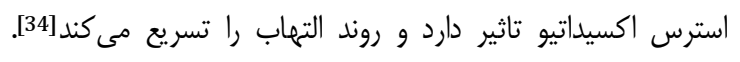

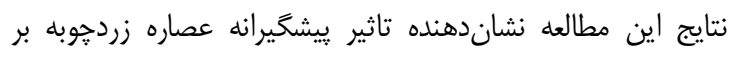

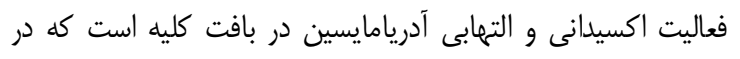

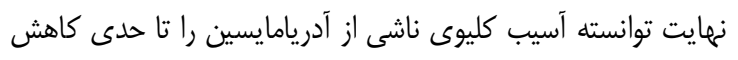
دهد. از محدوديتهاى اين مطالعه، زمانبربودن تهيه عصاره و كارهاى دهد

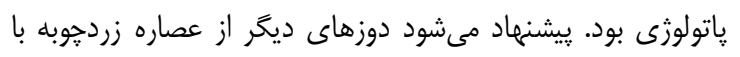


Qufeng Tongluo Recipe on expression of desmin and CD2AP proteins in adriamycin-induced nephropathy rats: An experimental research. Zhongguo Zhong Xi Yi Jie He Za Zhi. 2014;34(2):203-8. [Chinese]

24- Hommel E, Mathiesen ER, Aukland K, Parving HH. Pathophysiological aspects of edema formation in diabetic nephropathy. Kidney Int. 1990;38(6):1187-92.

25- You H, Lu Y, Gui D, Peng A, Chen J, Gu Y. Aqueous extract of Astragali Radix ameliorates proteinuria in adriamycin nephropathy rats through inhibition of oxidative stress and endothelial nitric oxide synthase. J Ethnopharmacol. 2011;134(1):176-82.

26- Franco R, Gut A, Ferrari-Spadotto A, Georgette J, Gavras I, Gavras H. Pressor mechanisms in adriamycininduced nephropathy with hypertension in rats. Hypertension. 1994;23(Suppl 1):246-9.

27- Kawamori T, Lubet R, Steele VE, Kelloff GJ, Kaskey $\mathrm{RB}$, Rao CV, et al. Chemopreventive effect of curcumin, a naturally occurring anti-inflammatory agent, during the promotion/progression stages of colon cancer. Cancer Res. 1999;59(3):597-601.

28- Wu X, An P, Ye B, Shi X, Dang H, Fu R, et al. Artemisinin ameliorated proteinuria in rats with adriamycin-induced nephropathy through regulating nephrin and podocin expressions. J Tradit Chin Med. 2014;34(1):63-8.

29- Wei M, Sun W, He W, Ni L, Cai X, Cheng Z, et al. Qiguiyishen decoction reduced the accumulation of extracellular matrix in the kidneys of rats with adriamycin-induced nephropathy. J Tradit Chin Med. 2014;34(3):351-6.

30- Mohan M, Kamble S, Satyanarayana J, Nageshwar M, Reddy N. Protective effect of Solanum torvum on Doxorubicin-induced hepatotoxicity in rats. Int J Drug Dev Res. 2011;3(3):131-8.

31- Elsherbiny NM, El-Sherbiny M. Thymoquinone attenuates Doxorubicin-induced nephrotoxicity in rats: Role of Nrf2 and NOX4. Chem Biol Interact. 2014;223:102-8.

32- Sharma OP. Antioxidant activity of curcumin and related compounds. Biochem Pharmacol. 1976;25(15):1811-2.

33- Mohebbati R, Shafei MN, Soukhtanloo M, Mohammadian Roshan N, Khajavi Rad A, Anaeigoudari A, et al. Adriamycin-induced oxidative stress is prevented by mixed hydro-alcoholic extract of Nigella sativa and Curcuma longa in rat kidney. Avicenna J Phytomed. 2016;6(1):86-94.

34- Koul A, Shubrant S, Gupta P. Phytomodulatory potential of lycopene from Lycopersicum esculentum against doxorubicin induced nephrotoxicity. Indian J Exp Biol. 2013;51(8):635-45. hypocholesterolemic effects in rabbits with experimental atherosclerosis. Atheroscler. 2000;147(2):371-8.

11- Nishiyama $T$, Mae $T$, Kishida $H$, Tsukagawa $M$, Mimaki $\mathrm{Y}$, Kuroda $\mathrm{M}$, et al. Curcuminoids and sesquiterpenoids in turmeric (Curcuma longa L.) suppress an increase in blood glucose level in type 2 diabetic KK-Ay mice. J Agric Food Chem. 2005;53(4):959-63.

12- Antony S, Kuttan R, Kuttan G. Immunomodulatory activity of curcumin. Immunol Invest. 1999;28(5-6):291303.

13- Gautam SC, Gao X, Dulchavsky S. Immunomodulation by curcumin. Adv Exp Med Biol. 2007;595:321-41.

14- Araujo CAC, Leon LL. Biological activities of Curcuma longa L. Mem Inst Oswal do Cruz. 2001;96(5):723-8.

15- Zima T, Tesar V, Crkovska J, Stejskalová A, Platenik J, Teminova J, et al. ICRF-187 (dexrazoxan) protects from adriamycin-induced nephrotic syndrome in rats. Nephrol Dial Transplant. 1998;13(8):1975-9.

16- Khorsandi L, Orazizadeh M. Protective effect of Curcuma longa extract on acetaminophen induced nephrotoxicity in mice. DARU. 2008;16(3):155-9.

17- Chromý V, Rozkošná K, Sedlak P. Determination of serum creatinine by Jaffe method and how to calibrate to eliminate matrix interference problems. Clin Chem Lab Med. 2008;46(8):1127-33.

18- Goering PL, Fisher BR, Noren BT, Papaconstantinou A, Rojko JL, Marler RJ. Mercury induces regional and cellspecific stress protein expression in rat kidney. Toxicol Sci. 2000;53(2):447-57.

19- Di Marco A, Arcamone F, Zunino F. Daunomycin (daunorubicin) and adriamycin and structural analogues: Biological activity and mechanism of action. In: Corcoran JW, Hahn FE, Snell JF, Arora KL, editors. Mechanism of Action of Antimicrobial and Antitumor Agents [Volume 3]. Berlin Heidelberg: Springer; 1975. pp. 101-28.

20- Sarhan M, El Serougy H, Hussein AM, El-Dosoky M, Sobh MA, Fouad SA, et al. Impact of bone-marrowderived mesenchymal stem cells on adriamycin-induced chronic nephropathy. Can J Physiol Pharmacol. 2014;92(9):733-43.

21- Liang C-l, Wu J-b, Lai J-m, Ye S-f, Lin J, Ouyang H, et al. Protection effect of Zhen-Wu-Tang on adriamycininduced nephrotic syndrome via inhibiting oxidative lesions and inflammation damage. Evid Based Complement Altern Med. 2014;2014:1-11.

22- Zhu C, Xuan X, Che R, Ding G, Zhao M, Bai M, et al. Dysfunction of the PGC-1alpha-mitochondria axis confers adriamycin-induced podocyte injury. Am J Physiol Renal Physiol. 2014;306(12):1410-7.

23- Wang Z, Liu JT, Sun WS, Li RP, Wang Y. Effect of 